Review

\title{
Pneumonic plague: incidence, transmissibility and future risks.
}

\author{
Charles Evans ${ }^{1}$
}

1 University of Birmingham, School of History and Cultures, Birmingham, UK, B15 2TT. Orchid ID: 0000001-9743-5075. c.m.evans@bham.ac.uk

\begin{abstract}
Pneumonic plague outbreaks are relatively infrequent in modern times but in the early part of the $20^{\text {th }}$ century, they were commonplace including several well-documented epidemics responsible for the deaths of thousands. The transmissibility of this disease seems to be discontinuous since in some outbreaks few transmissions occur, while in others, the progression of the epidemic is explosive. Modern epidemiological studies explain that transmissibility within populations is heterogenous with relatively few subjects likely to be responsible for most transmissions and that 'super spreading events', particularly at the start of an outbreak, can lead to a rapid expansion of cases. These findings concur with outbreaks observed in real-world situations. It is often reported that pneumonic plague is rare and not easily transmitted but this view could lead to unnecessary complacency since future risks such as the spontaneous incidence of anti-microbial strains, climate change leading to a disruption of natural cycles within plague foci and use of plague as a bioweapon cannot be discounted. Carers and first responders are vulnerable, particularly in poorer countries where access to medicines may be limited, outbreaks occur in inaccessible areas or where there is a lack of surveillance due to a paucity of funds.
\end{abstract}

\section{Introduction}

Plague is a life-threatening zoonotic disease caused by the bacterium Yersinia pestis (Yp) which is generally acknowledged by historians and biologists to have caused the $1^{\text {st }}$ and $2^{\text {nd }}$ pandemics, also known as the Plague of Justinian and the Black Death, as well as the ongoing $3^{\text {rd }}$ pandemic $[1,2]$. It now seems that this pathogen was endemic in the human populations of Eurasia dating at least 3,000 years ago with the suggestion that this ancestral strain of Yp could cause pneumonic plague but lacked the virulence factors necessary to cause bubonic plague although this interpretation of the data is subject to debate $[3,4]$. Several forms of plague are recognised, the most common being bubonic, septicaemic and pneumonic plague which are distinguished by their mode of transmission, infection site and symptomology. Bubonic plague is famously characterised by swellings of the lymphatic glands known as buboes and is usually the result of transmission from a mammalian host, via an insect vector. In this form plague is not readily transmittable from person-toperson although some workers believe that human ectoparasites, such as lice or fleas, can play a role under 
certain circumstances [5]. Septicemic plague, is characterised by high bacteraemia, without evidence of lymphatic swellings, usually resulting in overwhelming endotoxemia that is fatal if untreated promptly. In this case, the primary infection site is often a flea bite but the disease rapidly progresses to the septicaemic form if the lymphatic defences are breached [6]. Primary pneumonic plague, which is the focus of this paper, is typified by an overwhelming pneumonia, often accompanied by coughing and haemoptysis, and is transmitted between humans via droplet infection [7]. Secondary pneumonic plague can occur when the primary infection site is an insect bite but the vascular spread results in an infection in the lung which can then be transmitted from person to person by droplet infection. It is also the case that some individuals who are infected via the respiratory route may develop overwhelming sepsis before pneumonia and haemoptysis can develop; then cardiac failure may be sudden and brought about by slight exertion [8]. Pneumonic plague (PP) presents a significant threat to public health because, if untreated by antibiotics, it has a mortality rate approaching $100 \%$ [9]. It is also considered feasible by some that Yp in its aerosol form could be used as a biological weapon of war or in a terrorist attack [10].

In view of the undeniable lethality of the plague bacillus when introduced by droplet infection, PP has been the subject of considerable research interest $[8,9,11]$. However, it is frequently repeated that this form of the disease is rare $[12,13]$ with one research group maintaining that recent evidence indicates that interhuman transmission may be due mainly to human ectoparasites, such as body lice and fleas rather than aerosol transmission [14]. Furthermore, some investigators have stated that PP is highly contagious [15] whilst others have taken the view that it is 'not easily transmitted' some even suggesting that, in locations where protective masks are unavailable, and chemoprophylaxis is not routinely given to health workers, simple measures such as minimising contact time with patients or asking them to turn away whilst being examined are sufficient to protect against transmission [16]. If PP outbreaks are indeed rare events, and if the disease is not easily transmitted, perhaps it can be largely ignored as a significant danger to humans. However, the current opinion as expressed by the World Health Organisation remains as follows [17]:

\footnotetext{
"Pneumonic plague must be considered highly contagious whenever it occurs, although person-toperson transmission is most likely in cold humid environments coupled with overcrowding."
} 
It should also be noted that the current WHO advice on handling patients recommends 'droplet precautions' including patient isolation, spatial separation of at least two meters, mask wearing and appropriate post-exposure antimicrobial prophylaxis [18]. This paper seeks to review the evidence which might predict the likelihood of PP outbreaks in the future and, if they do arise, how easily will Yp transmit in a human population.

\section{The location and frequency of PPP outbreaks}

Yp remains established in persistent enzootic foci (the bacteria, an animal reservoir and a vector) found on all continents except Oceania. (Figure 1). It is especially at home in populations of small mammals, typically rodents, but even so, the range of infected species within a focus can be much wider than this and include coyotes, bobcats and black bears across the Western United States [19]. Some foci, for example those found across the territories of the Russian Federation and former Soviet republics are believed to be ancient [20] whilst others such as the island of Madagascar [12] or the Mid-West of America are more recent, being the product of communication and trade [19]. There is a risk of human plague wherever the presence of plague natural foci and human populations co-exist. Thus, plague epidemics tend to occur in Africa, Asia, and South America but more recently the most endemic countries include the Democratic Republic of Congo, Madagascar, and Peru [22].

Specifically, it had been observed that in Madagascar, which has remained a natural focus for plague since its introduction in 1898 [23], PP cases decreased during the second half of the $20^{\text {th }}$ century [24], whilst in a series of four epidemics from 1995 to 1998 the lack of pneumonic cases was said to be 'remarkable' - being attributable to the efficacy of plague control programmes, chemoprophylaxis for contacts and the intensity of control measures incorporating rapid recourse to health structures [25]. The World Health Organisation (WHO) also stated that "The decrease in the incidence of plague today is due primarily to the improvement of living standards and health services in many countries... and primary pneumonic plague, the most epidemic form of the disease, has been reduced nearly to zero" [26]. However, since these statements were made, however, we have witnessed a significant outbreak of plague in Madagascar (2017) when 2414 plague cases were reported of which $78 \%$ were pneumonic [27]. This outbreak exemplifies an alarming feature of plague in that it can seem seems to disappear indefinitely but then re-emerge suddenly, despite improvements in treatment and surveillance [28]. Since the start of the $20^{\text {th }}$ century, PP has presented itself as an assortment of both large and small epidemics worldwide. Early on, there were many recorded outbreaks 
in Africa, Asia, the Americas and Europe which were collated by Wu Lien-Teh in his 1926 Treatise [29]. Certainly, based on Wu's analysis it seems unconvincing to apply the adjective 'rare' to PP in the first quarter of the $20^{\text {th }}$ Century. It seems that the origin of this opinion can be traced back to the British Indian Plague Commission [30] (IPC) which concluded that:

"Pneumonic plague is highly contagious. It is, however, rare (less than 3 per cent. of all cases) and plays a very small part in the general spread of the disease."

The opinion has been restated more recently by Seal [13] who wrote:

"The incidence of pneumonic plague in India is generally below $1 \%$ and has never exceeded $3 \%$ in any year since 1895."

However, these views are not entirely consistent with the facts available at the time they were expressed, since a report compiled for the Municipal Commissioner on the plague in Bombay for the year ending $31^{\text {st }}$ May 1899 , based on the returns from hospitals in that city, stated that of 9493 cases, $16 \%$ had no buboes. $5.3 \%$ of the sample were identified as being primary pneumonic plague with an additional $3.7 \%$ identified as secondary pneumonic plague $[31,32]$. On their own, these statistics suggest that the figures given by the IPC are not universally representative whilst another problem which should be considered, when relying on statistics gleaned from hospital admissions, is that the frequency of presentation of PP and bubonic cases is likely to be skewed toward the bubonic types. This is because PP cases have a shorter duration of illness, a tendency towards incapacity and higher mortality than bubonic cases. Thus, the proportion of PP cases presenting is likely to be much lower than that of the bubonic cases. Also, evidence was obtained from a series of PP outbreaks in Punjabi villages which led the author to suggest that the incidence of PP varied in different parts of India and was more common in the comparatively cool climate of the Punjab [33]. Another report on plague in the Hughli-Chinsura [sic] municipality in Western Bengal, 1905 recorded that out of 254 cases recorded $28 \%$ were pneumonic, 53\% were bubonic and the remainder 'indeterminate' of which the latter were characterised by rapid death before the enlargement of glands or pneumonia could be detected [34]. Furthermore, earlier accounts of plague in Bombay (1897), Kathiawar (1817) and Pali (1839) all attest to a substantial number of pneumonic cases based on observed symptomatology [35,36]. It seems strange that evidence such as this did not find its way into the thinking of the IPC but Medicine in British India was, however, largely a militaristic enterprise undertaken by the Indian Medical Service which had been formed to provide a reserve of medical officers for duty with the Indian Army [37]. Possibly, in such an hierarchical 
organisation, challenges to accepted thinking, normally a desirable feature of scientific investigation, would not be encouraged.

Elsewhere, the IPC model was being questioned by William Simpson [38] who described an outbreak in Accra and surrounding villages of the Gold Coast in 1908 which ran in parallel with an epidemic of bubonic plague associated with a rat epizootic. Simpson [39] concluded that:

"Hitherto the usual percentage of pneumonic cases in an epidemic has not been observed to be high... But the epidemic on the Gold Coast shows that that percentage is not an invariable standard of relationship between the one and the other, and that, under certain conditions, the bubonic may be displaced by the pneumonic form, which may, in its turn, occupy the whole field of the outbreak".

The potentially serious nature of PP became clear in Manchuria, 1910-11 when an outbreak of this disease killed 60,000 people [40]. Such was the alarm caused by this event, that an international conference was convened at Mukden in 1911 attended by many of the world's infectious disease specialists [41]. This epidemic is the most frequently cited and though it was, perhaps, the most devastating of its type, it is by no means unique. Another major outbreak occurred in Manchuria in 1920 which killed approximately 10,000 people [40] and another in Shansi province, 1918 when 16,000 people are believed to have died [41]. Other outbreaks have been recorded in Kashmir, 1904 [42] which killed 1,423 individuals and Dakar, 1914 which accounted for at least 3,687 deaths [43]. Thus, whilst it true that from 1920 onwards there do not appear to have been outbreaks on such a scale, it seems prudent to take a cautious view and consider the factors that might provoke a re-emergence.

\section{The infectivity of pneumonic plague}

The infectivity of PP has been the subject of debate [44] with some arguing that the risk of infection is quite low under normal circumstances $[14,16]$. It is certainly the case that some investigators with personal field experience of dealing with PP outbreaks were struck by an apparent lack of transmissibility. For instance, one investigator [46] reporting on an outbreak of 37 cases of PP in the Kalahari, 1941, commented that:

"...what impressed me... was not the number of the cases but their paucity. It seemed almost incredible that so many close contacts should escape infection; for example, two or three men who slept for several nights in the same hut as one dying from pneumonic plague." 
Similar sentiments have been expressed in another report on an outbreak in Rangoon, 1945 when 16 deaths were recorded [47]. It does seem difficult to explain why a disease can, at times, generate substantial epidemics, yet, in some theatres, it appears to lack the ability to diffuse though the population and can only generate minimal outbreaks [48]. To provide answers to this question it is necessary to re-consider the problem in the light of modern developments in the understanding of respiratory disease transmission.

\subsection{The mechanism of transmission and factors influencing its efficiency}

PP is transmitted between individuals by droplet aerosols when infected individuals cough up sputum containing plague bacilli in large numbers. Strong \& Teague found that the effective range was limited to 4 meters, bacteria were not expelled during ordinary breathing and thus infection was likely to be limited to carers or those coming into intimate contact with a victim [49]. Indeed, recent observations show that close relatives and health-workers seem to be far more vulnerable than casual contacts [50,51,52]. However, this phenomenon is not peculiar to Yp transmission since factors such as social distancing, duration and quality of contact also influence transmission rates as in the case of SARS-Cov-2 [53] and respiratory diseases in general [54]. Factors such as crowding and cool, relatively humid conditions have also been associated with increased rates of PP transmission [42,55] but this is also a feature of respiratory diseases in general [56]. Furthermore, individual variables may not prove to be critical in all cases since, whilst there are specific references to workers being forced together by the cold in the Manchurian epidemics, the Shansi outbreak affected mainly domestic homes in villages [57]. Similarly, the outbreaks in Accra and elsewhere in Africa were clearly not dependent upon cold weather. What may be most significant, however, is that whilst respiratory diseases such as SARS-Cov-2 can be transmitted by fine aerosol particles which have the potential for longer-range transmission as well as droplet infection, PP transport in the air seems to be limited to droplet sized particles [54].

Another important factor is the short duration of illness of PP which, following an incubation period of 2-5 days, is generally around 2-4 days. It is thought that the infectious period starts after 20-24 hrs when the cough starts to project droplets indicating that the infectious period may only be 1-3 days long [58]. In addition, patients rapidly become moribund and lack the ability interact with the remaining population. Thus, a 
short infectious period coupled with immobility would seem to mitigate against the process of active transmission.

Other processes, however, may work to extend the infectious period. For instance, Strong \& Teague [55] also stated that:

\footnotetext{
"The idea that infection ... is caused entirely by particles of sputum expectorated by the patient $\ldots$ is erroneous. It follows ... that the wearing of masks and the proper covering of any surface of the skin where fresh abrasions are present are important... measures against plague infection".
}

This points to transmission by fomites which consist of both porous and nonporous surfaces, or objects, that can become contaminated with sputum containing pathogenic microorganisms and serve as vehicles in transmission. Fomites are a significant means of transmission of respiratory viruses and harmful bacteria and it is thought that a substantial portion of human respiratory tract infections are transmitted via contaminated hand contact with the mouth, eyes, and/or nostrils with subsequent transport to target tissue sites in the oroand nasopharyngeal regions $[59,60,61]$. Recent studies show that $Y$. pestis can survive for up to 5 days on porous and non-porous surfaces under optimal conditions of humidity and temperature [62] whilst early in the $20^{\text {th }}$ century, Wu Lien-Teh et al showed that $Y$. pestis, in expressed sputum, could survive for days, provided it was not exposed to sunlight or excessive heat [63]. Contaminated sputum was also found on the clothing of cadavers perhaps contributing to the high mortality of sanitary and burial-coolies in Manchuria [40]. Several recent studies confirm that funerial ceremonies are significant and indicate a period of infectiousness which may well extend beyond death $[12,24,43,64,65,66]$.

\subsection{The basic reproductive number $\left(\mathbf{R}_{0}\right)$ and the effective reproductive number $\left(\mathbf{R}\right.$ or $\left.R_{t}\right)$}

The basic reproductive number $\left(\mathrm{R}_{0}\right)$ is a key concept in epidemiology and may be defined as: "the expected number of secondary cases produced by a typical infected individual during its entire infectious period, in a population consisting of susceptibles only" [67]. Thus, if $\mathrm{R}_{0}<1$, each case will produce, on average, less than 1 secondary infection and the outbreak will die out, but if $\mathrm{R}_{0}>1$, each case will produce more than one secondary infection thus maintaining the outbreak. However, is usually the case that the transmission frequency decreases with time as potentially susceptible hosts die and are eliminated from the population or susceptibles start to avoid contact with infected individuals and/or public health measures are implemented. 
More usefully, therefore, for real time predictions the time dependent reproduction number (or effective reproduction number) $\mathrm{R}_{\mathrm{t}}$ ( or $\mathrm{R}$ ) may be calculated where $\mathrm{R}_{\mathrm{t}}<\mathrm{R}_{0}$ and may be defined as the expected number of new infections caused by an infectious individual in a population where some individuals may no longer be susceptible [68]. Gani \& Leach were the first to use $\mathrm{R}_{0}$ for the analysis of eight small outbreaks of PPP and calculated values that ranged between 0.7 and 3.0 with an average of 1.3 [69]. This early study has frequently been quoted as evidence to confirm the lack of transmissibility for PP since $\mathrm{R}_{0}$, thus calculated, was close to unity $[8,16]$. Nevertheless, mathematical epidemiologists point out that $\mathrm{R}_{0}$ is a mathematically defined quantity [70]. It certainly makes less sense from a biological or demographical perspective since population estimates depend upon assumptions which may not hold true in the real world. For instance, the calculation may assume that every pair of individuals in a population has the same chance of interacting at any given time but unsurprisingly, this is seldom the case. In other words, the transmission potential of individuals is heterogenous [71]. Delamater et al have also pointed out that $\mathrm{R}_{0}$ is not a biological constant for a given pathogen as its value will vary according to numerous extrinsic biological, sociobehavioral, and environmental factors that govern transmission within the observed population [72]. They also argue that $\mathrm{R}_{0}$ is estimated with various mathematical models which can easily be misrepresented, misinterpreted, and misapplied. For these reasons, we may expect different values of $\mathrm{R}_{0}$ for diverse epidemics of the same pathogen using the same statistical method and similar variations if we analyse the same epidemic using different statistical methods. It is telling that some outbreaks have been analysed by more than one research group with results that are substantially different. For example, Nishiura et al calculated $\mathrm{R}_{0}$ for outbreaks in Mukden, 1946 and Madagascar, 1957 and obtained values of 2.8-3.4 for the former and 3.0 for the latter [73]. This contrasts with the values of 0.9 and 1.1 calculated by Gani \& Leach [69]. Elsewhere, a study on the 2Madagascan (2017) PP epidemic estimated $\mathrm{R}_{0}$ to be 1.7 [74] but in another study it was found to range between 6.5 and 7.1 depending on model assumptions [75]. For an outbreak which occurred in Johannesburg, 1904, recent calculations indicated an $\mathrm{R}_{\mathrm{t}}$ of 4.0 at its highest point declining to 1.0 after a period of 10 days suggesting a likely high value of $\mathrm{R}_{0}$ for this epidemic which might have been the consequence of crowding in insanitary conditions [64]. Variations in the calculated value of $\mathrm{R}_{0}$ is not peculiar to PP since they are also observed for measles, West African Ebola and influenza virus [72]. Thus, whilst $\mathrm{R}_{0}$ remains a valuable epidemiological concept, it is clearly unhelpful if attempts are made to use it as a single, definitive measure of 
infectiousness for PP in all situations and additional approaches are needed to explain why this disease can generate large epidemics in some cases but small outbreaks elsewhere.

\subsection{Heterogenous transmission and the 80:20 rule}

Following an investigation of various infectious agents, Woolhouse et al proposed an empirical relationship suggesting that typically, $20 \%$ of the host population contributes at least $80 \%$ of the net transmission potential as characterised by the reproduction number $\mathrm{R}_{0}$ [76]. This implies that roughly $20 \%$ of the most infectious individuals are responsible for $80 \%$ of transmissions with the corollary that a substantial number will not transmit at all. The extent to which individual infectivities depart from the population $\mathrm{R}_{0}$ is measured by the negative binomial dispersion parameter, $\mathrm{k}$ and there is a large body of work attesting to its significance in the study of epidemics. Galvani \& May argued that a consequence of this model is that having such small numbers of potential transmitters tends to generate pronounced stochastic fluctuations in the initial stages of the epidemic and so an heterogeneously infectious emerging disease will be less likely to generate an epidemic, but if sustained, the resulting epidemic is more likely to be explosive [77]. Lloyd-Smith et al investigated eight infectious diseases and concluded that 'superspreading events' (SSEs) in which certain individuals infect unusually large numbers of secondary cases are a normal feature of disease spread [78]. The mechanism of infection described for PP may also contribute to heterogenicity since it has been found that while some patients cough up large amounts of bloody sputum, others produce very little, or none [58] which is an illustration of the general rule that there is considerable variation in the ability of individual subjects to express aerosols containing airborne pathogens [79]. Hinckley et al [80] considered the relevance of SSEs in their study of all PPP cases in the USA from 1900 to 2009 and suggested that the outbreaks in Oakland [81] and San Francisco [82] involved SSEs which were material in the initial stages and were responsible for the relatively larger size of these outbreaks even though their estimate of $\mathrm{R}_{0}$ was close to unity. Examples of SSEs where a single case can infect a large cluster of victims can be found elsewhere in the literature $[43,52,83,84]$.

\section{How PPP outbreaks start.}

The conventional view has been that primary pneumonic plague infection results from contact with patients suffering from bubonic plague and have gone on to develop secondary infection in the lungs $[40,85]$. There are several reports which suggest that travellers, infected with the bubonic form of the disease, are 
particularly likely to develop secondary lung infection and thus introduce the disease, in its pneumonic form, to new areas $[11,86,87,88]$. However, the relationship between bubonic and pneumonic outbreaks is not absolute since, in some cases, it has been observed that the pneumonic phase of an outbreak can precede the bubonic as was found to be the case in Johannesburg (1904), the Punjab (1907) and Dakar $(1914)[33,44,62]$ whilst in another, no bubonic cases were recorded [23]. Moreover, there have been many well-documented instances of pneumonic plague being acquired from handling, hunting and skinning sylvatic rodents in areas where the disease is enzootic. In particular, gerbils, marmots and ground squirrels, have been implicated $[81,89]$ and Russian plague scientists have long held the view that pneumonic plague could be readily transmitted in this way thus the hunters of the Tarbagan marmot, a known reservoir of the plague bacillus, transmitted plague to the itinerant Chinese population during the Manchurian outbreaks of 1911 and 1921 [90]. This hypothesis was initially disparaged by the influential Wu Lien-Teh of the North Manchurian Plague Prevention Service but he later changed his mind and conceded the point $[63,91]$. Plague is still an occupational hazard for marmot hunters in China today, where most hunters in Qinghai take antimicrobial drugs as an effective prophylactic although deaths still occur from time to time [92]. Other sylvatic non-rodent species have occasionally transmitted the disease. For instance, a pneumonic plague outbreak was recently recorded in India where the index case was a hunter who had killed and skinned a wildcat thus contracting pneumonic plague before passing it on to family and close contacts [93]. A similar event occurred in the USA when a wildlife biologist carried out a necropsy on a mountain lion carcass [94]. It is also clear that this phenomenon has also been found to extend to companion animals such as cats and dogs which appear to act as intermediate vectors between sylvatic species and humans. For instance, Gage et al [95] conducted a review of human plague cases in America caused by exposure to cats infected with Y. pestis. Of the 23 cases reviewed, 5 were of primary pneumonic plague thought to be the result of inhaling infectious respiratory droplets, or airborne oral secretions, during face-to-face contact with the animals. These patients had no contact with patients suffering from secondary pneumonic plague. None of the remaining cases of bubonic plague (including one septicaemic plague victim) evidenced inguinal or femoral buboes, which are typical of infection via flea bite, but axial and cervical buboes which were more easily explained by scratches and bites from the cats themselves.

\section{How PPP epidemics end.}


Where an infected population is both isolated and limited in size, we may expect the outbreak to expire naturally for want of fresh contacts. In general, several types of intervention both voluntary and involuntary, seem to be effective in attenuating outbreaks of PP. Isolation of sick people is especially effective and proved to be especially decisive in Johannesburg in 1904 [64] and Oakland, USA [82] both events occurring before the availability of antibiotic treatments. Flight through fear, or simply avoidance, may reduce potential contacts although it may also have the effect of dispersing the disease leading to outbreaks elsewhere $[64,96]$. It has also been suggested that some epidemics of pneumonic plague mature into a 'pulmonary form' characterised by an absence of the production of sputum leading to a 'spontaneous' decline [40]. Furthermore, the International Plague Conference in Mukden, 1911 considered that climatic influences could have contributed to a decline although there did not appear to be a loss of virulence of the pathogen [41]. Apart from the physical isolation of patients, wearing of masks etc. the most significant intervention of recent years has been the development and use of anti-microbial drugs but these need to be administrate within $24 \mathrm{hrs}$ after the onset of symptoms to be effective [97]. Unfortunately, the development of a suitable vaccine, which is capable of being licensed, remains elusive [98].

\section{Future Risks}

\subsection{Anti-microbial resistance}

It is now well established that bacteria are able to exchange DNA by horizontal transfer in the natural environment by well understood mechanisms [99]. Under natural conditions in Madagascar, Yp, has been shown to acquire antibiotic resistance plasmids and, in the laboratory, the transfer of an antibiotic resistance plasmid from an Escherichia coli to Yp has been observed in the mid-gut of fleas [100,101,102]. However, it is likely that this is not the only mechanism though which Yp can acquire resistance. In China, resistance to streptomycin was identified in a clinical isolate of Yp obtained in 1996 from a PPP outbreak in in the Qinghai-Tibet Plateau plague focus. This resistance was the result of a mutation in the rpsL gene and was not the result of horizontal transfer [103]. Similar resistance to streptomycin (the current first-line treatment in Madagascar), due to a spontaneous point mutation in the rspL gene, has been recorded in fatal PP cases in two separate locations in Madagascar from isolates sampled in 2013 and 1987 leading the authors of this study to 
conclude that unique antimicrobial resistant strains of Yp continue to arise in Madagascar and can be transmitted during PP epidemics [104]. Worryingly, one such strain was found to be resistant to all antibiotics recommended for therapy (chloramphenicol, streptomycin and tetracycline) and prophylaxis (sulphonamides and tetracycline) [100]. A more optimistic view, however, has been taken by some workers who have examined strains of Yp on a worldwide basis and found a lack of multidrug resistance arguing that there appears to be little or no selective advantage for Yp to maintain a multidrug resistance plasmid generated in natural cycles [105].

\subsection{Climate change}

There is no doubt that climate variables modulate the dynamics and distribution of infectious diseases and the animal vectors which carry them. However, whilst it is expected that climate change will affect infectious disease patterns, it is becoming clear that shifts in climate could drive conditions towards the optimum for transmission in some areas whilst pushing conditions away from the optimum in others [106]. The optimum conditions for flea growth and reproduction, as well as the natural cycles of crop production and rodent populations, are particularly sensitive to such variables. Five-year lagged temperature and aridity index seem to have been significant determinants of plague outbreaks in pre-industrial Europe in that plague outbreaks associate with cold dry spells - opposite to some studies showing that effects may be different in different spatio-temporal settings [107]. In British India 1898-1949, moderate mean humidity levels of between $60 \%$ and $80 \%$ were associated with plague outbreaks [108]. Specifically, cold but humid conditions have been specified for the propagation of PP [109]. In this respect some of the most severe PP epidemics took place in exceptionally cold conditions $[42,43]$ but epidemics in Madagascar and Dakar indicate that this not an essential prerequisite. Another consequence of climate change is the aggravation of poverty in $3^{\text {rd }}$ world countries which could lead to civil conflict and forced migration whilst lack of funds might lead to a diminution of surveillance systems which are essential for identification of re-emerging infectious diseases in such areas [110].

\subsection{Plague as a bioweapon}

Some authors consider that Yp appears to be a good candidate agent for a bioterrorist attack [111] whilst simulations have been carried out in the USA as directed by Congress [112]. There are reports that the 
Japanese in World War II released plague infected fleas over Chinese cities with some success [113] and in historical times, the Mongol army are said to have hurled plague-infected cadavers into the besieged Crimean city of Caffa thus transmitting the disease to the inhabitants [114]. The use of plague as a bio-weapon fraught with the difficulty of achieving a spread of aerosolised bacteria over a wide area although the WHO [115] suggested a scenario where $50 \mathrm{Kg}$ of Yp could be released over a city of 5 million people thus causing the disease in 150,000 people of whom 36,000 might be expected to die. Nevertheless, if the aim of the terrorist is to induce terror, social disruption and economic cost and not the induction of large numbers of casualties per se, the use of smaller amounts of plague bacteria might be effective. For example, a natural outbreak of pneumonic plague which started in Surat, India in 1994 and spread to other cities in India lasted for little over 2 weeks but created an unprecedented panic that had global repercussions [116].

\subsection{Threats to first responders and health workers.}

The experience of British Doctors working in Bombay hospitals from 1898 to 1899, where most infections treated were of the bubonic type, was that few, if any, attendants on the plague wards were attacked thus leading one practitioner to declare "...that one of the safest places during the epidemic is the ward of a sanitary plague hospital" which was a sentiment repeated by that the British Indian Plague Commission at that time [30,32]. However, with the advent of epidemics in which PP was the prevailing form of the disease, the position changed dramatically. Following the epidemics in Manchuria (1911) and Shansi (1918), Wu pointed out that although the disease often attacked poor people, doctors and nurses were also frequently attacked and he also noted the exceptionally high number of infections in sanitary police and burial coolies [4]. Similarly. in an outbreak in Cape Town, 1901 five of the female nursing staff contracted PP and died [117]; in an outbreak in Ecuador (1939) which caused 17 deaths, four nursing sisters and one doctor died [118], whilst in the outbreak in Oakland, USA (1919) involving 13 deaths, two of the deceased were physicians and two were nurses [81]. One important characteristic, common to these three outbreaks was that inadequate precautions were taken by the medical staff since there was nothing to suggest that PP was involved in the early stages and anti-microbial drugs were not yet available. Clearly, in present times, the WHO guidelines on managing such outbreaks need to be followed whenever Yp is suspected.

\section{Conclusions}


It seems evident that in the early part of the $20^{\text {th }}$ Century, PP epidemics were nor rare but occurred frequently around the globe. During this period several substantial epidemics, involving the death of several thousands of people, took place in India, Manchuria, China and West Africa although none of these progressed into a distinct global pandemic. There has been a relative quiescence in plague during the latter part of the $20^{\text {th }}$ Century but the outbreaks of PP in Surat, 1994 and Madagascar, 2017 are a reminder to us of the potential for this disease to re-emerge. When considering the transmissibility of PP, the situation is complex, as indeed it is with other respiratory diseases, but in the real world there are two factors which particularly limit the ease with which spread can occur. Firstly, it seems likely that transmission through the air takes place via respiratory droplets rather than smaller diffusible particles and is therefore likely to take place over shorter distances. Secondly, the relatively short infectious period coupled with rapid immobilisation should lead to fewer transmissions. However, many transmissions take place passively between patients and their carers and visitors them and there is strong evidence implicating contact with cadavers and funeral rites so that the infectious period can effectively extend beyond death. From the world of mathematical epidemiology, modern studies can help to explain why a disease outbreak can disappear rapidly in some theatres yet lead to more extensive epidemics elsewhere. It is not enough to rely on a single measure of transmissibility such as $\mathrm{R}_{0}$ to predict the likelihood of future outbreaks of a disease as this measure tends to be predicated on a mean population statistic. Heterogeneity in population transmission dynamics and the role of SSEs in the initial stages of an outbreak are equally important since they point to the likelihood of rapid extinctions and/or explosive outbreaks which may be difficult to control and these modelling predictions appear to match the real-world experience.

Future risks which could possibly facilitate re-emergence of Yp in its pneumonic form may include the evolution of strains which are resistant to anti-microbial agents which, apart from well-rehearsed clinical measures such as isolation, mask wearing etc., have proven to be the most potent weapons against Yp. Whilst the current position is such that one may to suppose that outbreaks are likely to be limited to regions where plague is enzootic. However, with modern means of transport it cannot be assumed that this will be the case in future. As an example, the PP outbreak which commenced in Surat, India (1994) spread to Delhi, Bombay and Calcutta due to the movement of contacts via the train network [96] in a similar way to the epidemic in Manchuria (1911) [119]. Clearly, the possibility of diffusion through air transport adds a new dimension of risk. The advent of climate change brings a new level of uncertainty but it is not clear how such 
variations will affect the probability of new outbreaks occurring since some climatic factors act to supress transmission within enzootic foci while others promote it. However, if climate change leads to migration and instability of political systems which then lead to conflict, we may expect that the delivery of health services will be disturbed and surveillance systems may deteriorate - especially in economically poor areas which may already be handicapped by superstition, lack of resources and inaccessibility. As others have pointed out, it is easy to forget plague in the $21^{\text {st }}$ century, seeing it as an historical curiosity [120] but complacency cannot be allowed to become the default option.

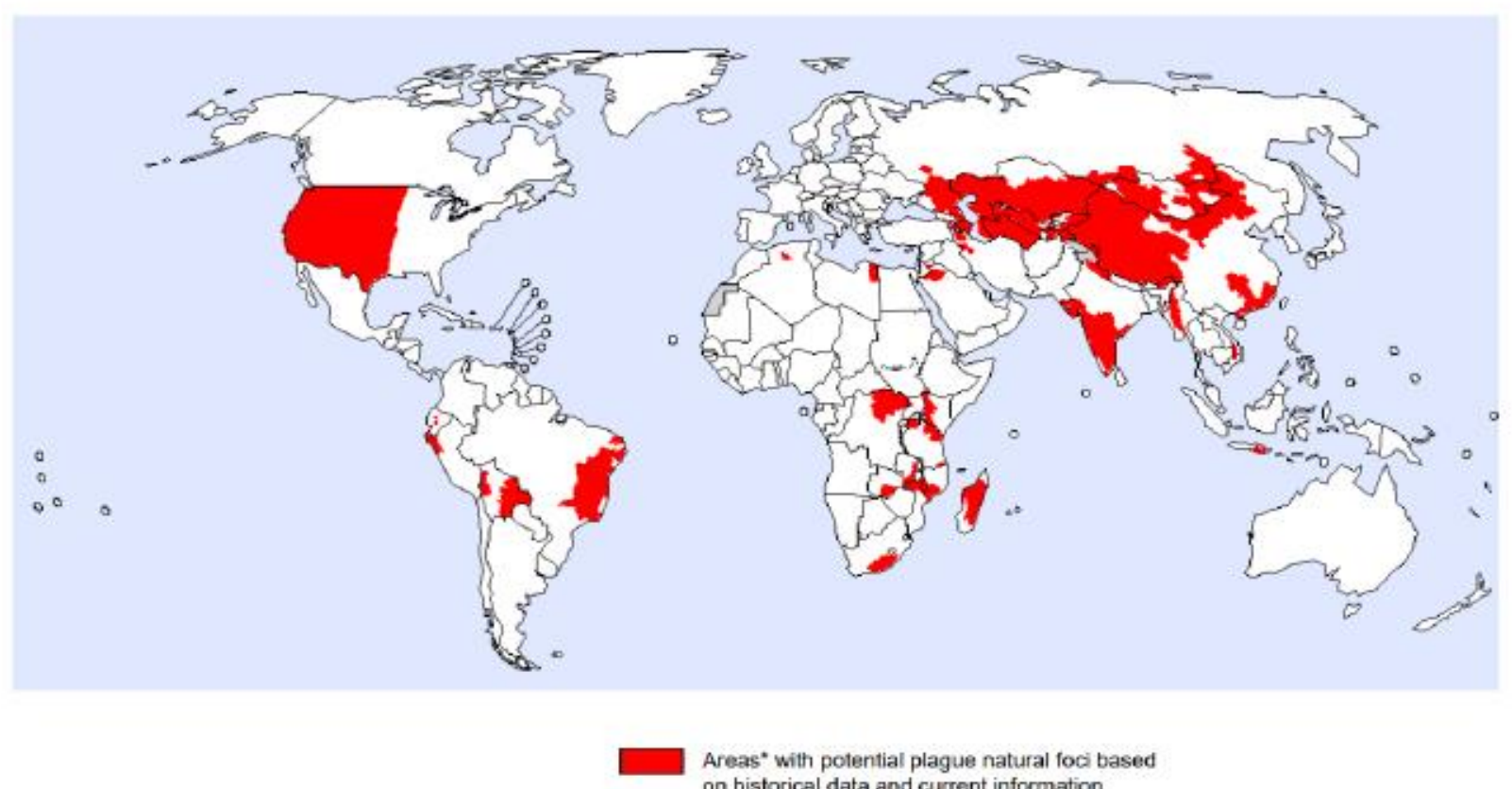
on historical data and current information

\footnotetext{
- First administrative level representation Source: WHO/PED, as of 15 March 2016
}

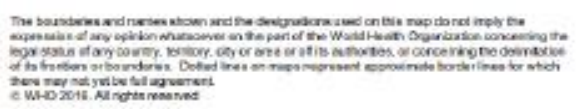

Figure 1. Global distribution of natural plague foci as of March 2016

Acknowledgments: The author wishes to thank the University of Birmingham for providing facilities for this research.

Conflicts of Interest: The author declares no conflict of interest in the interpretation of data; in the writing of the manuscript, or in the decision to publish it.

Biopic: The author gained a PhD in Zoology from Swansea University in 1979 and went on to contribute to a number of biological and medical research projects. He is currently in receipt of an Honorary Research Fellowship at the School of History and Cultures at Birmingham University, UK. He is currently investigating plague epidemics in both modern and historical contexts.

\section{References}


1. Green, M. H. Editor's introduction. In: Pandemic disease in the medieval world: rethinking the Black Death. M. H. Green ed., ARC Medieval Press, Kalamazoo and Bradford, 2014, 27-62.

2. Perry, R. D.; Fetherston, J. D. Yersinia pestis - etiologic agent of plague. Clin. Microbiol. Rev. 1997, 10, $35-66$.

3. Rasmussen, S.; Allentoft, M. E.; Neilsen, K.; Orlando, L. et al. Early divergent strains of Yersinia pestis in Eurasia 5,000 years ago. Cell. 2015, 163, 571-582.

4. Susat, J.; Lübke, H.; Immel, A.; Brinker, U. et al. A 5,000-year-old hunter-gatherer already plagued by Yersinia pestis. Cell Rep. 2021, 35, 1-8.

5. Drancourt, M.; Houhamdi, L.; Raoult, D. Yersinia pestis as a telluric, human ectoparasite-borne organism. Lancet Infect. Dis. 2006, 6, 234-241.

6. Gage, K..L.; Beard, C.B. Plague. In: Infectious Diseases, 4th ed.; Cohen, J.; Powderly, W.G.; Opal, S. M. Eds.; Elsevier: Amsterdam, Netherlands, 2017, Volume 2, pp. 1078-1084.

7. Strong, R.; Teague, O. Studies on pneumonic plague and plague immunisation. II Method of transmission of the infection in pneumonic plague and the manner of spread of the disease during the epidemic. Phillippine J. Sci. 1912, 7, 137-156.

8. Erickson, D. L.; Hinnebusch, B. Pneumonic plague. In: Anderson, B.; Friedman, H.; Bendinelli, M. (eds) Microorganisms and Bioterrorism. Infectious Agents and Pathogenesis. Springer, Boston, MA.

9. Pechous, R. D.; Sivaraman, V.; Stasulli, N. M.; Goldman, W. E. Pneumonic plague: the darker side of Yersinia pestis. Trends Microbiol. 2016, 24, 190-197.

10. Dennis, T. D. Plague as a biological weapon. In: Bioterrorism and infectious agents: a new dilemma for the $21^{\text {st }}$ century. Fong, I. W.; Alibek, K. eds. Springer Science and Business Media, Inc.3 New York, 2009, 7-70.

11. Meyer, K. Pneumonic plague. Microbiol. Mol. Biol. Rev. 1961, 25, 249-261.

12. Andrianaivoarimanana, V.; Kreppel, K.; Elissa, N.; Duplantier, J-M. et al., Understanding the persistence of plague foci in Madagascar. PLOS Neg Trop Dis. 2013, 7, 1-8.

13. Seal, S. C. (1960). Epidemiological studies of plague in India 1. The present position. Bull. Wrld. Hlth. Org., $1960,23,283-292$.

14. Barberi, R.; Signoli, M.; Chevé, D.; Tzortzis. S. et al. Yersinia pestis: the natural history of plague. Clin. Microbiol. Rev. 2021, 34, e00044-19. 
15. Oyston, P. C. F. Plague virulence. J. Med. Microbiol. 2001, 50, 1015-1017.

16. Kool, J. L. Risk of Person-to-Person Transmission of Pneumonic Plague. Clin. Infect. Dis. 2005, 40, $1166-1172$.

17. Dennis, D. T.; Gage, K. L.; Gratz, N.; Poland, J. D.; Tikhomirov, E. Plague Manual : Epidemiology, distribution, surveillance and control. Wrld. Hlth. Org. (Geneva Switzerland). 1999, 32, 135-165.

18. World Health Organisation. Interregional meeting on prevention and control of plague. Antananarivo, Madagascar 1 - 11 April 2006. Wrld. Hlth. Org. (Geneva Switzerland).

19. Bevins, S. N.; Chandler, J. C.; Barrett, N.; Schmit, B. S. et al, Plague exposure in mammalian wildlife across the Western United States. Vector Borne Zoonotic Dis. 20, 10, 1-8.

20. Kutyrev, V. V.; Eroshenko, G. A.; Motin, V. L.; Nosov, N. Y. et al. Phylogeny and classification of Yersinia pestis through the lens of strains from the plague foci of Commonwealth of Independent States. Front. Microbiol. 2018, 9, 1-11.

21. Andrianaivoarimanana, V.; Kreppel, K.; Elissa, N. Duplantier, J-M. et al., Understanding the persistence of plague foci in Madagascar. PLOS Neg Trop Dis. 2013, 7, 1-8.

22. WHO, Plague fact sheet. https://www.who.int/news-room/fact-sheets/detail/plague, 2017 (accessed; 11 November, 2021).

23. Brygoo, E. R.; Epidémiologie de la peste à Madagascar. Arch. l'Institut Pasteur Madagascar. 1966, 35, 1-139.

24. Migliani, R.; Chanteau, S.; Rahalison, L., Ratsitorahina, M. et al. Epidemiological trends for human plague in Madagascar during the second half of the 20th century: A survey of 20900 notified cases. Trop. Med. Int. Heal. 2006, 11, 1228-1237.

25. Boisier, P.; Rahalison, L.; Rasolomaharo, M.; Ratsitorahina, M. et al. Epidemiologic features of four successive annual outbreaks of bubonic plague in Mahajanga, Madagascar. Emerg. Infect. Dis. 2002, 8, 311.

26. World Health Organization (WHO). Plague Outbreak Madagascar: External Situation Report 14. WHO Reg Off Africa. 2017, (December), 1-9.

27. Randremanana, R.; Andrianaivoarimanana, V.; Nikolay, B.; Ramasindrazana, B. et al. Epidemiological characteristics of an urban plague epidemic in Madagascar, August-November, 2017: an outbreak report. Lancet Infect. Dis. 2019, 19, 537-535. 
28. Neerinckx, S.; Bertherat, E.; Leirs, H. Human plague occurrences in Africa: an overview from 1877 to 2008. Trans. R. Soc Trop. Med. Hyg. 2010, 104, 97-103.

29. Wu, L-T. A Treatise on Pneumonic Plague. Geneva: Publications of the League of nations. Health Organisation.; 1926.

30. Lamb, J. T. W. The etiology and epidemiology of plague: a summary of the work of the Plague Commission. 1908. Calcutta: Superintendent of Government Printing, India.

31. Harvey, W. L. Report of the municipal commissioner on the plague in Bombay for the year ending $31^{\text {St }}$ May 1899. Bombay: “Times of India steam press” 1899. pp 158-159.

32. Bannerman, W. B. The spread of plague in India. J. Hyg. (Lond). 1906, 6, 179-211.

33. Gill, C. A. A note on the epidemiology of pneumonic plague. Ind. Med. Gaz. 1909 (April), 135-137.

34. Crawford, D. G. A report on the epidemic of plague in Hughli-Chinsura Municipality January to May 1905. [Abridged from an official report.] Ind. Med .Gaz. 1905 (October), 371-377.

35. Childe, L. F. Remarks on the occurrence of Plague Pneumonia. Brit. Med. J. 1897 (May) 1215-1216.

36. Nathan, R. The Plague in India 1896, 1897. Vol. II. 1898, Government Central Printing Office, Simla, Appendix II. pp 59-106.

37. McDonald, D. The Indian Medical Service. A short account of its achievements 1600 - 1947. Proc R. Soc. Med. 1955, 49, 13-17.

38. Baker, R. A.; Bayliss, R. A. William John Ritchie Simpson (1855-1931): Public health and tropical medicine. Med. Hist. 1987, 31, 450-465.

39. Simpson, W. J. Report on plague in the Gold Coast in 1908. 1909, London: J \& A Churchill.

40. Wu, L-T.; Chun, J. W. H.; Pollitzer, R. Clinical observations upon the Manchurian plague epidemic, 1920-21. J. Hyg. (Lond). 1923, 21, 298-306.

41. Report of the International Plague Conference held at Mukden, April, 1911. 1912, Manila Bureau of Printing.

42. Wu, L-T.; Plague in the orient with special reference to the Manchurian outbreaks. J. Hyg. (Lond). 1922, $21,62-76$.

43. Mitra, A. The plague in Kashmir. Ind Med Gaz. 1907, April, 133-138.

44. M'Bokolo, E. M. Peste et société urbaine à Dakar: 1'épidémie de 1914. Cah d'etudes afrcanes. 1982, $22,13-46$. 
45. Cowling, P.; Moss, P. Infectivity of pneumonic plague. BMJ, 1994, 309, 1369.

46. Gale, G. W. An outbreak of pneumonic plague in the Kalahari. S. A. Med. J. 1941, 25, 369-373.

47. Wynne-Griffith, G. Pneumonic plague in Rangoon. The Lancet, 1948 (Apr), 625-627.

48. Hinckley, A. F.; Biggerstaff, B. J.; Griffith, K. S.; Mead, P. S. Transmission dynamics of primary pneumonic plague in the USA. Epidemiol Infect. 2012, 140, 554-560.

49. Strong, R.; Teague, O. Studies on pneumonic plague and plague immunisation. II Method of transmission of the infection in pneumonic plague and the manner of spread of the disease during the epidemic. Phillippine J. Sci. 1912, 7, 137-156.

50. Joshi, K.; Thakur, J..S.; Kumar, R.; Singh, A. J. et al. Epidemiological features of pneumonic plague outbreak in Himachal Pradesh, India. Trans. R. Soc. Trop. Med. Hyg. 2009, 103, 455-460.

51. Ramasindrazana, B.; Andrianaivoarimanana, V.; Rakotondramanga, J. M.; Birdsell, D. N. et al. Pneumonic plague transmission, Moramanga, Madagascar, 2015. Emerg. Infect. Dis. 2017, 23, 521-524.

52. Wang, H.; Cui, Y.; Wang, Z.; Wang, X.; Guo, Z.; Yan, Y. et al. A dog-associated primary pneumonic plague in Qinghai Province, China. Clin. Infect. Dis. 2011, 52, 185-190.

53. Bazant, M. Z.; Bush, J. W. M. A guideline to limit airborne transmission of COVID - 19. PNAS 2021, 118, e2018995118.

54. Leung, N. H. L. Transmissibility and transmission of respiratory viruses. Nature, 2021, 19, 528-545.

55. Teague, O.; Barber, M. A. Studies on pneumonic plague and plague immunisation. III Influence of atmospheric temperature upon the spread of pneumonic plague. Phillippine J Sci. 1912, 7, 157-172.

56. Moriyama, M.; Hugentobler, W. J.; Iwasaki, A. Seasonality of respiratory viral infections. Ann. Rev. Virol. 2010, 7, 83-101.

57. Wu, L-T. The 1917-18 Shansi epidemic (Pneumonic). Appendix I, Studies upon the plague situation in North China, Nat. Med. J. China, 1929, 25, 373-385.

58. Pollitzer, R. Plague studies. 8. Clinical Aspects. Bull. Wld. Hlth .Org. 1953, 9, 59-129.

59. Boone, S. A.; Gerba, C. P. Significance of fomites in the spread of respiratory and enteric viral disease. Appl. Environ. Microbiol. 2007, 73, 1687-1696.

60. Pittet, D.; Dharan, S.; Touveneau, S.; Sauvan, V.; Perneger, T. V. Bacterial contamination of the hands of hospital staff during routine patient care. Arch Intern Med. 1999, 159, 821-826. 
61. Nicas, M.; Best, D. A study quantifying the hand-to-face contact rate and its potential application to predicting respiratory tract infection. J. Occup. Environ. Hyg. 2008, 5347-352.

62. Rose, L. J.; Donlan, R.; Banerjee, S. N.; Arduino, M. J. Survival of Yersinia pestis on environmental surfaces. Appl Environ Microbiol. 2003, 69, ,2166-2171.

63. Wu, L-T.; Chun, W. H.; Pollitzer, R. Plague in Manchuria: I. Observations made during and after the second Manchurian plague epidemic of 1920-21. II. the rôle of the tarbagan in the epidemiology of plague. J. Hyg. (Lond).. 1923, 21, 307-358.

64. Evans, C. M.; Egan, J. R.; Hall, I. Pneumonic plague in Johannesburg, South Africa, 1904. Emerg. Infect. Dis. 2018, 24, 95-102.

65. Maule Clark, B.; Goldburg, S. Pneumonic plague : recovery in a proved case. South African Med. J. $1943,17,57-60$.

66. Jullien, S.; de Silva, N. L.; Garner, P. Plague transmission from corpses and carcasses. Emerg. Infect. Dis. 2021, 27, 2033-2041.

67. Heesterbeek, J. A. P.; Dietz, K. The concept of R0 in epidemic theory. Stat Neerl. 1996, 50, 89-110.

68. Gostic, K. M.; McGough, L.; Baskerville, E. B.; Abbott, S. et al. Practical considerations for measuring the effective reproductive number, $\mathrm{R}_{\mathrm{t} .}$ PLoS Comput Biol., 2020, 16, e1008409.

69. Gani, R.; Leach, S. Epidemiologic determinants for modeling pneumonic plague outbreaks. Emerg. Infect. Dis. 2004, 10, 608-614.

70. Nishiura, H,; Chowell, G. The effective reproduction number as a prelude to statistical estimation of time-dependent epidemic trends. Mathematical and Statistical Estimation Approaches in Epidemiology. 2009, 103-121.

71. Lloyd-Smith, J. O.; Schreiber, S. J.; Kopp, P. E.; Getz, W. M. Superspreading and the effect of individual variation on disease emergence. Nature. 2005, 438, 355-359.

72. Delamater, P. L.; Street, E. J.; Leslie. T. F.; Yang, Y. T.; Jacobsen, K. H. Complexity of the basic reproduction number $\left(\mathrm{R}_{0}\right)$. Emerg. Infect. Dis. 2019, 25, 1-4.

73. Nishiura, H.; Schwehm, M.; Kakehashi, M.; Eichner, M. Transmission potential of primary pnemonic plague: time inhomogeneous evaluation based on historical documents of the transmission network. $J$. Epidemiol. Community Health, 2006, 60, 640-645. 
74. Tsuzuki, S.; Lee, H.; Miura, F.; Chan, Y.H. et al. Dynamics of the pneumonic plague epidemic in Madagascar. Euro. Surveill. 2017, 22, 1-6.

75. Nguyen, V. K.; Parra-Rojas, C.; Hernandez-Vargas, E. A. The 2017 plague outbreak in Madagascar: Data descriptions and epidemic modelling. Epidemics. 2018, 25, 20-25.

76. Woolhouse, M. E. J.; Dye, C.; Etard, J-F.; Smith, T.; Charlwood, J. D.; Garnett, G. P. et al. Heterogeneities in the transmission of infectious agents: Implications for the design of control programs. Proc. Natl. Acad. Sci. 1997, 94, 338-342.

77. Galvani, A. P.; May, R. M. Epidemiology: Dimensions of superspreading. Nature. 2005;438(7066):293-295.

78. Lloyd-Smith, J. O.; Schreiber, S. J.; Kopp, P. E.; Getz, W. M. Superspreading and the effect of individual variation on disease emergence. Nature. 2005, 438, 355-359.

79. Edwards, D. A.; Man, J. C.; Brand, P.; Katstra, J. P, et al. Inhaling to mitigate exhaled bioaerosols. PNAS. 2004, 101, 17383-17388.

80. Hinckley, A. F.; Biggerstaff, B. J.; Griffith, K. S.; Mead, P. S. Transmission dynamics of primary pneumonic plague in the USA. Epidemiol Infect. 2012, 140, 554-560.

81. Kellogg, W. H. An epidemic of pneumonic plague. Am. J. Public Health (N Y). 1920, 10, 599-605.

82. Dickie, W. M. Plague in California 1900-1925. Plague Pathology and Bacteriology. In: Proc. Conference of State \& Provincial Health Authorities of North America, 1926. 1926, 30-78.

83. Wu, L-T. The second pneumonic plague epidemic in Manchuria, 1920-21: I. A general survey of the outbreak and its course. J. Hyg. (Lond). 1923, 21, 262-288.

84. Seal, S. C.; Prasad, G. Further notes on the incidence of pneumonic plague cases in Gaya (Bihar). Ind. Med. Gaz. 1949, Sept., 408-413.

85. Pollitzer, R. A review of recent literature on plague. Bull. Wld. Hlth. Org. 1960, 23, 313-400.

86. Brygoo, E. R.; Gonon, M. L’épidémie de peste pulmonaire de Doany en octobre 1957. Arch. Inst. Pasteur. 1958, 13, 865-936.

87. Simpson, W. J. A treatise on plague dealing with the historical, epidemiological, clinical, therapeutic and preventative aspects of the disease. Cambridge University Press, Cambridge. 1905. pp. 211-212.

88. Petrie, G. F.; Todd, R.; E.; Skander, R.; Himly, F. A report on plague investigations in Egypt. J. Hyg. 1924, 22, 117-150. 
89. Baltazard, M.; Bahmanyar, M.,; Mofidi, Ch.; Seydian, B. Le foyer de Peste du Kurdistan 1. Recherches dans le foyer. Bull. Org. Mond. Sante. 1952, 5, 441-472.

90. Loukaskin, A..S. The Tarbagan or the Transbaikalian Marmot as a carrier of plague. Extrait des comptes rendus du XIIème congres international de zoologie - Lisbonne. 1935, 2097-2111.

91. Wu, L-T. North Manchuria Plague Prevention Service Reports (1911-1913). Ed: Wu Lien-Teh. Cambridge University Press, Cambridge 1914.

92. Li., M.; Song, Y. ; Li, B. ; Yang, R, et al. Asymptomatic Yersinia pestis infection, China. Emerg. Infect. Dis. 2005, 11, 1494-1496.

93. Gupta, M. L.; Sharma, A. Pneumonic Plague, Northern India, 2002. Emerg. Infect. Dis. 2007, 13, 664666.

94. Wong, D.; Wild, M. A.; Walburger, M. A.; Higgins, C. L. et al. Primary pneumonic plague contracted from a mountain lion carcass. Clin. Infect. Dis. 2009, 49, e33-e38.

95. Gage, K. L.; Dennis, D. T.; Orloski, K. A.; Ettestad, P. et al. Cases of cat-associated human plague in the Western US, 1977-1998. Clin. Infect. Dis. 2000, 30, 893-900.

96. Dutt, A, K,; Akhtar, R.; McVeigh, M. Surat plague of 1994 re-examined. Southeast Asian J Trop. Med Public Health. 2006, 37, 755-760.

97. Butler, T. Plague history: Yersin's discovery of the causative bacterium in 1894 enabled, in the subsequent century, scientific progress in understanding the disease and the development of treatments and vaccines. Clin. Microbiol. Infect. 2014, 20, 202-209.

98. Sun, W.; Singh, A. K. Plague vaccine: recent progress and prospects. Npj Vaccines, 2019 4, 11.

99. Hall, P. J.; Brockhurst, M. A.; Harrison, E. Sampling the mobile gene pool: innovation via horizontal gene transfer in bacteria. Phil. Trans. R. Soc. B. 2017, 372, 20160424.

100. Galimand, M.; Guiyoule, A.; Gerbaud, G.; Rasoamanaana, B. et al. Multidrug resistance in Yersinia pestis mediated by a transferable plasmid. New England J. Med. 1997, 337, 677-680.

101. Guiyoule, A.; Gerbaud, G.; Buchrieser, C.; Galimand, M. et al. Transferable plasmid-mediated resistance to streptomycin in a clinical isolate of Yersinia pestis. Emerg. Infect. Dis. 2001, 7, 43-48.

102. Hinnebusch, B. J.; Rosso, M-L.; Schwan, T. G.; Carniel, E. et al. High-frequency conjugative transfer of antibiotic resistance genes to Yersinia pestis in the flea midgut. Mol. Microbiol. 2002, 2, 249-354. 
103. Dai, R.; He, J.; Zha, X.; Wang, Y. et al. A novel mechanism of streptomycin resistance in Yersinia pestis: mutation in the rpsL gene. PLoS Negl. Trop. Dis. 2021, 15, e0009324.

104. Andrianalvoarimanana, V.; Wagner, D. M.; Birdsell, D. N.; Nikolay, B. et al. Transmission of antimicrobial resistant Yersinia pestis during a pneumonic plague outbreak. Clin. Infect. Dis. 2021, 20, 1-8.

105. Urich, S. K.; Chalcraft, L.; Schriefer, M. E.; Yockey, B. M.; Petersen, J. M. Lack of antimicrobial resistance in Yersinia pestis isolates from 17 countries in the Americas, Africa, and Asia. Antimicrob. Agents Chemother. 2012, 56, 555-558.

106. Thomas, M. B. Epidemics on the move: Climate change and infectious disease. PLoS Biol, 2020, 18, e3001013.

107. Yue, R. P. H.; Lee, H. F. Pre-industrial plague transmission mediated by the synergistic effect of temperature and aridity index. BMC Infect Dis, 2018, 18, 134.

108. Tennant, W. S. D.; Tildesley, M. J.; Spencer, S. E. F.; Keeling, M. J. Climate drivers of plague epidemiology in British India, 1898-1949. Proc. R. Soc. B. 2020, 287, 20200538.

109. Teague, O.; Barber, M. A. Studies on pneumonic plague and plague immunisation. III Influence of atmospheric temperature upon the spread of pneumonic plague. Phillippine J. Sci. 1912, 7, 157-172.

110. De Vries, L.; Koopmans, M.; Morton, A.; Van Baal, P. The economics of improving global infectious disease surveillance. BMJ Global Health. 2021, 6, e006597.

111. Bossi, P.; Tegnell, A.; Baka, A.; Van Loock, F; et al. Bichat guidelines for the clinical management of plague and bioterrorism-related plague. Euro. Surveill. 2004, 9, 1-3.

112. Inglesby, T. V.; Grossman, R.; O’Toole, T. A plague on your city: observations from TOPOFF. Clin. Infect. Dis, 2001, 32, 436-445.

113. Reidel, S. Biological warfare and bioterrorism: a historical review. BUMC Proc. 1974, 17, 400-406.

114. Wheelis, M. Biological warfare at the 1346 siege of Caffa. Emerg. Infect. Dis. 2004, 8, 971-975.

115. World Health Organisation, 1970. Health aspects of chemical and biological weaponry. Geneva. Switzerland.

116. Dutt, A.K.; Akhtar, R.; McVeigh, M. Surat plague of 1994 re-examined. Southeastern Asian J. Trop. Med. Pub. Health. 2006, 37, 755-760.

117. Mitchell, F. K. The plague in Cape Town in 1901 and its subsequent establishment as an endemic disease in South Africa. S. A. Med. J. 1983, June, 17-19. 
118. Murdock, J. R. Pneumonic plague in Ecuador during 1939. Public Health Reports, 1940, 55, $2172-$ 2178.

119. Farrar, R. Plague in Manchuria. J. Royal Soc. Med. 1912, 5, 1-24.

120. Stenseth, N.C.; Atshabar, B. B.; Begon, M.; Belmain, S. R. et al. Plague: past, present, and future. PLoS. Med. 2008, 5, e3, 009-13. 